\title{
The relevance problem in the analysis of argumenta- tive texts - A pragma-dialectical reconstruction
}

\section{The relevance problem}

As for awkwardness, for researchers in Discourse Analysis, the relevance problem is somewhat similar to the problem of alienation for Marxists. The rationale of their joint venture is, as it were, to come to terms with this problem; it is too fundamental and too general to be dealt with definitively in one stroke. So, we will not try to do that, but restrict ourselves to clarifying the relevance problem in the analysis of argumentative texts containing oral or written argumentation in which an effort is made to resolve a difference of opinion. ${ }^{1}$

First, we will quote some authors who have looked into the relevance problem.

In her article, 'On getting the point' (1982), the American linguist Tracy cites the following dialogue:
A: I don't know what to major in.
B: uhm
A: I'm really torn between the practical and the interesting. I'd pro- bably be able to get a good job if I majored in accounting (...). But, I really like anthropology. It's fun learning about all those exotic cultures. But, look at Jim, he majored in anthropology in college. Now Jim's working in an office earning nothing.
B: Yeah, I ran into him the other day and we decided to play rac- quetball (1982, 281-282).

According to empirical research, language users usually regard the remark concerning racquetball as irrelevant when interpreting this dialogue. Tracy is interested in these kinds of empirical observations concerning relevance.

In their book Logical Self-defense (1983), the Canadian informal logicians Johnson and Blair devote some space to relevance. They deal with a woman's reaction to the Report of the Bertrand Commission from

1 This is a first report on a joint research project called 'Relevance in argumentative discourse' we are carrying out at the Netherlands Institute for Advanced Study (NIAS) together with Douglas Walton. 
1981, in which the oil companies are accused of unlawful conspiracy in order to freeze the prices of petrol. This lady wrote the following:

Bertrand and the commissioners must be out to lunch. In no possible way could he have one lousy shred of evidence to support their allegations. I can say this because my husband has been working for the oil company for 30 years and the company has always been good to him. To say that the industry my husband works for has been ripping off the public for years really irks me $(1983,177)$.

According to Johnson and Blair, the position of the lady stems from her 'egocentric investment': her husband is an employee of an oil company, he has always been loyal to this company, and she is loyal to him. Whether or not his employer has always been good to her husband does not affect the question of the freezing of the oil prices. Therefore, Johnson and Blair accuse the lady of using an irrelevant argument. Johnson and Blair are interested in making such judgements concerning relevance.

These two examples, which can easily be augmented by examples from other authors, make it clear that relevance is approached from various angles and that there are rather different conceptions of relevance (or irrelevance). An encompassing perspective that connects the various conceptions is lacking. In our opinion, though, such a perspective should be developed, as the various conceptions of relevance refer to related components of text coherence, which represent different aspects of the relevance-spectrum. Therefore, we think that it makes sense to maintain the term relevance as a general term. In order to be able to do so in a responsible way, we will start from some global features of relevance which apply to all cases.

Relevance (or lack of relevance) refers to the relation between explicit or implicit parts of an oral or written text. Relevance (or lack of relevance) is tied to a certain objective: only in the light of this goal is the one part of the text relevant or irrelevant to or with respect to the other. Relevance (or lack of relevance) does not primarily refer to the formal relation between text fragments but to the functionality of the relation between the communicative and interactional intentions which can be ascribed to the language users who have put forward the text fragments concerned. ${ }^{2}$

\footnotetext{
2 Here, we must refrain from elaborating upon these points of departure by precizating the notion of functionality, specifying the communicative and interactional intentions which play a part and formally characterizing the relevance relation between text fragments.
} 
To put it briefly: one part of a text is relevant to the other if a relation exists between these text fragments that is functional in light of a certain objective. The general relevance problem, then, is to determine whether or not such a functional relation exists between text fragments when given a particular goal in a given case.

\section{Divergent approaches to relevance}

Differences in angles of approach lead to specific conceptualizations of the idea of a 'functional relation', although the authors concerned usually do not, at least not explicitly, acknowledge that they are specific. In the literature on relevance, a global distinction can be made between two approaches.

First, there are authors who opt for an interpretative angle and who have, in principle, a descriptive approach. This group counts linguistically and sociologically or psychologically oriented researchers such as Tracy (1982), Dascal (1977), Jackson and Jacobs (1983), Sanders (1980), Sperber and Wilson (1986) and Werth (1981). They place the relevance problem, as a matter of course, into the context of the interpretation of 'speech events' and restrict the concept of relevance to interpretative relevance.

Relevance problems dealt with in this framework are for instance 'In what way do the participants in a conversation determine what counts as a relevant sequel to what has been said before?' and 'When can utterance A be interpreted as a relevant reaction or a relevant sequel to utterance B, e.g. as the granting or rejection of a request or as an answer to a question?'

The extract quoted from Tracy about playing racquetball is a clear illustration of interpretative irrelevance.

Second, there are authors who opt for an evaluative angle and who have, in principle, a normative approach. Logically oriented researchers, be it formal or informal logicians, such as Johnson and Blair (1983), Govier (1985), Iseminger (1986), Schlesinger (1986) and the representatives of the so-called standard treatment of fallacies belong to this group. They place the relevance problem without any ado in the context of the evaluation of arguments and restrict the concept of relevance to evaluative relevance.

Relevance problems which are dealt with in this framework are, for instance, 'Should a personal attack, an appeal to authority, an appeal to pity, threatening with sanctions or pointing at the consequences of a standpoint in an argument always be rejected as irrelevant?' 
The extract quoted from Johnson and Blair about the woman who put forward an irrelevant argument about the freezing of the petrol prices is a clear illustration of evaluative irrelevance.

It is characteristic of both aproaches that the concept of relevance is simply being monopolized, without taking into account that by doing so, the relevance problem is seriously limited, whereas the necessary connection between interpretation and evaluation is neglected. The two approaches of relevance will diverge more and more - and never the twain shall meet.

\section{The analysis of texts}

Normally, language use is aimed at understanding as well as acceptance: someone who makes a request not only wants it to be understood that he has requested something, but he also wants his request to be granted; someone who explains something not only wants his explanation to be understood but he also wants his explanation to be accepted, et cetera. Irrespective of whether it concerns short stretches of discourse or large texts, the interpretation always anticipates an evaluation, and the evaluation always presupposes an interpretation. As a consequence, scholars of discourse must envisage how the descriptive and the normative approach to texts can be linked with each other in such a way that the diverging angles converge.

In order to be able to deal adequately with more complex discourse, such as most argumentative texts, an analysis of the discourse that provides a sensible connection between the interpretation and the evaluation has to take place. A sound evaluation requires that the right evaluative questions are being asked, and in order to make this happen systematically, the interpretation, as a rule, has to undergo certain analytic transformations.

Analysing a text means looking at the text that is interpreted by the listener or reader from a specific viewpoint ensuing from the objective of the analysis. The analyst views the textual reality as it were with the help of a special pair of spectacles which makes the particular aspects which he is interested in more visible. He focusses on certain phenomena, so that he gets a better picture of some things, whereas other things fade away or disappear, more or less like in an X-ray. Starting from the interpretation, he thus achieves an analytical overview that can serve as point of departure for the evaluation.

Depending on the objective of the analysis, different kinds of analyses that also require different kinds of spectacles may be necessary. An ana- 
lysis aimed at revealing emotional tensions, for instance, may require psycho-analytical spectacles; an analysis aimed at detecting means of persuasion, rhetorical spectacles, et cetera. Because the psychoanalyst has other interests than a rhetorician, his analysis must be based on another theoretical model than that of the rhetorician. The Freudian model will be more suitable to him than a persuasion model.

First of all, of course, an appropriate theoretical model must be available for the analysis. Otherwise, it is no use to attempt an analysis and, for that matter, it will be very hard to execute. In order to be able to reveal the points which are of consequence for the evaluation, the analyst must have recourse to an ideal model that enables him to distinguish between what is relevant in the light of the goal concerned and what is not. For this, the ideal model must be explicitly formulated and theoretically accounted for.

\section{A pragma-dialectical reconstruction of argumentative texts}

When analysing argumentative discourse, we employ the pragmadialectical model, which makes it possible to identify the crucial moves. Argumentative discourse is, then, considered to be part of a critical discussion aimed at resolving a difference of opinion - this is the dialectical point. According to the model, a critical discussion proceeds in four stages: in the confrontation stage, the difference of opinion is defined; in the opening stage, the starting-points for resolving the difference are identified; in the argumentation stage, pro- and contra-argumentation is advanced to resolve the difference; in the concluding stage, the outcome of the discussion is established. The ideal model indicates which types of speech acts can, at each of these stages, contribute to the resolution of the difference of opinion - this is the pragmatic point (van Eemeren and Grootendorst 1984, 1987).

Normally, not all four stages of a critical discussion are explicitly and completely represented in this order in an argumentative text; and also speech acts are performed which are not included in the ideal model or whose function is not immediately clear. Therefore, at first glance, irrelevance seems to prevail, but at second glance this need not be so. The analysis is aimed at determining the dialectical relevance calibre of an argumentative text by verifying to what extent it can be reconstructed as a critical discussion. If there is reason enough to do so in a cyclic process of analysis, one or more transformations are carried out which separate the relevant elements from the "genuinely" irrelevant ones (van Eemeren 1986). 
In this way, in an analytic overview all those, and only those, elements are systematically brought together which are functional in view of the dialectical objective. In order to be able to do this, however, some clarification is needed of the problem of dialectical relevance.

\section{Differentiation of the problem of dialectical relevance}

No relation of relevance exists between sentences which are put together at random, but in ordinary language use this situation will hardly ever occur. Verbal communication and interaction do not take place by means of individual sentences but by means of inter-related speech acts by which the speaker or writer tries to achieve certain communicative and interactional effects on the listener or reader, and which can be more or less complex. In case of problems of interpretative relevance, the listener or reader will almost automatically try to find a goal that puts the one speech act in a functional relation to the other - and, as a rule, he will easily succeed in this, even if with sentences whose occurrence on the same piece of paper is only coincidental.

In a pragma-dialectical analysis, relevance connections are also sought for, but in a calculated and systematic way: in view of the specific insight that the analysis must provide, the interpretation is, as it were, programmed by putting the text fragment to be analysed into the perspective of the resolving of differences of opinion, and then by checking whether the speech acts that are performed are functional within this framework. In doing this, the ideal model of a critical discussion serves as a guideline.

According to the ideal model, not all speech acts are functional at every stage of the process of resolving a difference of opinion: their relevance is linked to a specific stage in the resolving process and to the specific (sub) goal that is aimed for in that stage. Lack of functionality of a speech act may have to do with the particular stage at which it is performed. When dealing with the problem of dialectical relevance, a specification is required of the exact domain in which the speech act under consideration is relevant. Furthermore, the object of dialectical relevance must be specified. The functionality of a speech act need not be questionable on all points: the issue may be limited to a certain component of it. A specification is required of the exact aspect of the speech act whose relevance is at stake. Finally, lack of functionality of a speech act may be of various sorts. This means that a specification is also needed of the exact nature of the relevance being referred to. 
With the help of the pragma-dialectical theory, the notion of dialectical relevance can be differentiated along these three dimensions: the domain dimension, the object dimension and the nature dimension. ${ }^{3}$

The central question with regard to the domain dimension is what range the relevance has. Depending on the range, various contexts of relevance can be distinguished in this dimension, such as opening stage relevance, concluding stage relevance, and, if the whole speech event is involved, overall relevance. For example, analytical observations can be made concerning the relevance of a speech act in the argumentation stage.

The central question with regard to the object dimension is of which component of the speech event the relevance is being considered. Depending on the component involved, various aspects of relevance can be distinguished in this dimension, such as the relevance of propositions and the relevance of communicative forces. For example, analytical observations can be made concerning the relevance of a certain proposition in the argumentation stage.

The central question with regard to the nature dimension is what kind of relevance is at stake. Depending on the sort of relevance involved, various types of relevance can be distinguished in this dimension, such as order relevance, clarity relevance, completeness relevance and reliability relevance. For example, analytical observations can be made concerning the completeness relevance of propositions in the argumentation stage.

It may be worth noting that, unlike Grice, we think that the scope of the relevance problem is not restricted to the maxim of relation. For example, saying too much (which amounts to a violation of the maxim of quantity) leads to another type of relevance problem, as is reflected in ordinary language use when people talk about irrelevant repetitions et cetera. We think that in dealing with relevance, all four Gricean conversational maxims (or their equivalents in some other theoretical framework) should be taken into account, and problems of relevance play a part in all four categories. So, on the one hand, we agree with Sperber and Wilson and other critics of Grice that relevance not only pertains to

3 In our opinion, when dealing with relevance problems, these three dimensions always play a part. However, their implementation depends on the theoretical starting-point sensuing from the perspective deemed to be the mostappropriate for dealing with a particular sort of speech event or text genre. Here, we have restricted ourselves toproviding a pragma-dialectical implementation for argumentative discourse and texts. 
the maxim of relation, and that a more encompassing conception of relevance is needed, but, on the other hand, we do not think that the maxim of relation can be skipped, and we do not agree with Sperber and Wilson that Grice's maxims can be replaced by a single principle of relevance (1981, 170).

The various combinations of aspects, contexts, and types of relevance can be represented in a dialectical relevance cube, with one co-ordinate level representing the object dimension, another co-ordinate level for the domain dimension and the third co-ordinate level for the nature dimension.

With the help of this specification, the problem of dialectical relevance can be differentiated, and each problem of dialectical relevance can be characterized in a well-grounded, consistent and clear manner. In this way, various categories of dialectical relevance problems can be distinguished, so that in the analysis, the most appropriate approach can be selected for dealing with the relevance problems at stake.

\section{An exemplary pragma-dialectical reconstruction}

In order to illustrate how in a pragma-dialectical reconstruction the problems arising in analysing argumentative discourse as part of a critical discussion can be dealt with, it might be enlightening to start from an arbitrarily chosen argumentative text. 
Suppose someone says to somebody else:

Must we move this thing any further? Or would you rather leave it here?

Probably, an ordinary language user will not see any problem here: two questions are asked with respect to the intentions of the person being addressed, and the second question offers an alternative to the possibility suggested in the first question. The matter becomes less clear, however, if more information is supplied concerning the context in which these questions have been asked. The extract is taken from a conversation between two people who are moving a piano: a mover and his assistant. The mover, who has just been quoted, knows that the piano should go to the second floor. They have reached the first floor and the young hand has just said:

We will never get that piano to the second floor. God knows why that woman wants it there. Let's have a fag.

It is clear now that the initial interpretation can hardly be maintained. So, then, what is the point of the mover's questions? We have a relevance problem here which must be dealt with in the analysis.

In doing this, we make use of the pragma-dialectical ideal model, with the distribution of speech acts over the various discussion stages. In view of the fact that they have only got to the first floor and that it is clear to the mover that the piano has to go to the second floor, the question 'Must we move this thing any further?' cannot be a real question and the question 'Or would you rather leave it here?' cannot refer to a genuine alternative.

After his colleague's remark that it is an impossible job and after his eagerness to have a break, there is reason to assume that by asking 'Must we move this thing any further?', the mover is confronting his colleague who shows signs of wanting to chuck it in. Therefore, it is justified to check whether this question can also be reconstructed as expressing a standpoint, so that it may be analysed as part of the confrontation stage of an emerging critical discussion. In that case, it might also be sensible to check if his second question, 'Or would you rather leave it here?', cannot be part of the argumentation stage, because in ordinary conversation, confrontation, as a rule, leads to an argumentative 'repair' (van Eemeren 1987 and Jackson and Jacobs 1983).

After the ideal model of a critical discussion has thus fulfilled a heuristic function in the analysis of the organization in stages, provisional 
characterisations can be given of the types of relevance which are at stake here. According to the analysis, the first question would be a rhetorical question that functions indirectly as a standpoint in the confrontation stage:

(In my opinion) That piano must be moved further

and the second question would be a rhetorical question that functions indirectly as an argument in the argumentation stage:

(For) You cannot leave it here

This means that the apparent irrelevances in these cases are of the following types: clarity irrelevance of the communicative force in the confrontation stage, and clarity irrelevance of the communicative force in the argumentation stage, respectively.

These characterisations, however, are only justified if it is justified in both cases to reconstruct these text fragments dialectically, by means of the substitution transformation, so that the lack of clarity is being removed and the apparent irrelevant questions can be replaced by a standpoint and an argument, respectively. Of course, the mere fact that the model indicates that something might be the case does not prove that it really is the case - otherwise, anything could be reconstructed as relevant. That the two questions may indeed be reconstructed as a standpoint and an argument should be accounted for in the analysis.

For brevity's sake, in showing how this can be done, we restrict ourselves to the second question. In the reconstruction of the question 'Or would you rather leave it here?' as an argument, among other things, the insight plays a part that because of the general Communication Principle in the absence of a good reason for doing so, no pointless, superfluous, insincere, incomprehensible or non-fitting speech acts may be ascribed to language users. If taken literally, the mover's question 'Or would you rather leave it here?' would be superfluous (because the mover knows that the piano cannot be left on the first floor), but there is no good reason for assuming that he abandons the Communication Principle altogether. All the same, he would violate the preparatory condition for asking a question, namely that the questioner does not yet know the answer. Therefore, it should be checked if he may have some intention other than asking a question.

The violation of the superfluity rule which takes place if the mover asks for the sake of asking, has been redressed if his question is taken to be an assertion. Then, he has asked a rhetorical question in which he has 
in fact made an assertion, so that he still observes the Communication Principle. Obviously, this assertion is not superfluous, for it seems not to have sunk in with the assistant that it is definitely the case that the piano must be moved to the second floor.

However, because the Communication Principle also implies that there should be a fitting relation between consecutive speech acts, it is necessary to check whether this reconstruction provides such a relation. In doing this, the correctness conditions for the performance of speech acts can be used again. Earlier on, the mover who asks the question has put forward a standpoint which he may assume to be doubted by the addressee. This means that a condition for accepting this standpoint has not been fulfilled. By means of his second question 'Or would you rather leave it here?', the mover now tries to make clear (in an ironic manner) that the correctness conditions for the standpoint that the piano must be moved further are actually fulfilled. This implies that this second question should not merely be reconstructed as an assertion, but also as an argument for the standpoint that the piano must be moved further. For a correct performance of the speech act of putting forward the standpoint that something must be moved, the preparatory condition has to be fulfilled which is that there is a good reason to move it. By means of his assertion in the form of a rhetorical question, which is to be analysed as an argument, the mover indicates that this condition has been fulfilled and thus tries to overcome any doubts about it. In this way, the second question is analysed as an argumentative 'repair' aimed at resolving the brewing difference of opinion about the moving of the piano, or preventing it from becoming a real issue.

In a similar way, an account can be given for the reconstruction of the first question of the mover, 'Must we move this thing any further?', as an assertion which serves as a standpoint. In both cases, the reconstruction amounts to carrying out a substitution transformation that, in this context, remedies the apparent irrelevance, as a consequence of unclarity, of the communicative force.

Herewith, we have illustrated, for one type of relevance problem, how problems of analysis can be dealt with by a pragma-dialectical approach. Similar reconstructions can be made for problems of analysis concerning other categories of relevance. In this way, an adequate point of departure is created for the evaluation. When such an evaluation is carried out, a question that seemed interpretatively irrelevant, may prove to be analytically relevant because it serves as an argument, but evaluatively irrele- 
vant because this argument is a fallacy in which an unwarranted appeal is made to authority. Of course, much more remains to be said about this subject, but in this paper we only wanted to show how a pragma-dialectical reconstruction can provide an analysis of an argumentative text that can serve as an intermediary between the interpretation and the evaluation of argumentative discourse when dealing with the relevance problem.

\section{Litterature}

Dascal, Marcelo (1977): Conversational Relevance, in: Journal of Pragmatics 1, 309328.

Eemeren, Frans H. van (1986): Dialectical Analysis as a Normative Reconstruction of Argumentative Discourse, in: Text, 6-1, 1-16.

Eemeren, Frans H. van (1987): For Reason's Sake: Maximal Argumentative Analysis of Discourse, in: F.H. van Eemeren et al. (eds.): Argumentation: Across the Lines of Discipline. Dordrecht/Providence: Foris 1987, 201-216.

Eemeren, F.H. van and R. Grootendorst (1987): Het analyseren en beoordelen van betogende teksten, in: Tijdschrift voor Taalbeheersing, 9-1, 48-66.

Govier, Trudy (1985): A Practical Study of Argument. Belmont, Cal.: Wadsworth.

Haft-van Rees, M.A. (1985): Relevantie van uitingen in argumentatieve teksten, in: W.K.B. Koning (ed.), Taalbeheersing in theorie en praktijk. Dordrecht: Foris 1985, 46-54.

Iseminger, Gary (1986): Relatedness Logic and Entailment, in: Journal of Non-Classical Logic, 3-1, 5-23.

Jacobs, Scott and Sally Jackson (1983): Speech Acts Structure in Conversation; Rational Aspects of Pragmatic Coherence, in: R.T. Craig and K. Tracy (eds.), Conversational Coherence: Form, Structure and Strategy. Beverly Hills: Sage 1983, 47-66.

Johnson, Ralph H. and J. Anthony Blair (1983): Logical Self-defense. Toronto: McGrawHill.

Sanders, R.E. (1980): Principles of Relevance: A Theory of the Relationship between Language and Communication, in: Communication and Cognition, 13-1, 77-95.

Schlesinger, George N. (1986): Relevance, in: Theoria, 52, 57-67.

Sperber, Dan and Deirdre Wilson (1986): Relevance. Communication and Cognition. Oxford: Blackwell.

Tracy, Karen (1982): On Getting the Point: Distinguishing 'Issues' from 'Events', an Aspect of Conversational Coherence, in: Communication Yearbook, 5, 279-301.

Walton, Douglas N. (1982): Topical Relevance in Argumentation. Amsterdam etc.: John Benjamins.

Werth, Paul (1981): The Concept of 'Relevance' in Conversational Analysis, in: P. Werth (ed.), Conversation and Discourse. London: Croom Helm 1981, 129-155.

Wilson, Deirdre and Dan Sperber (1981): On Grice's Theory of Conversation. In: Paul Werth (ed.), Conversation and Discourse. London: Croom Helm 1981, 155-179. 